\title{
Risk related surveillance following colorectal polypectomy
}

\author{
G Nusko, U Mansmann, Th Kirchner, E G Hahn
}

Background: Patients who have had a colorectal adenoma are likely to develop a metachronous adenoma and therefore need to be kept under surveillance. It is essential to avoid unnecessary examinations by tailoring the frequency of follow up examinations to individual risk.

Methods: A total of 3134 patients undergoing endoscopic removal of colorectal adenomas were prospectively recorded on the Erlangen Registry of Colorectal Polyps between 1978 and 1996. A multivariate analysis of 1159 patients on long term follow up was performed to identify risk factors determining surveillance intervals for patients with metachronous adenomas of advanced pathologythat is, adenomas $>10 \mathrm{~mm}$ or with high grade dysplasia or invasive carcinoma.

See end of article for authors' affiliations

.....................

Correspondence to: Dr G Nusko, Department of Medicine I, University of Erlangen,

Krankenhausstraße 12, 91054 Erlangen, Germany; gerhard.nusko@ med l.imed.uni-erlangen.de

Accepted for publication 16 October 2001
Results: Univariate analysis revealed that sex, parental history of colorectal carcinoma, and characteristics of the initial findings-that is, size, multiplicity, and amount of villous structure-were significant predictors of metachronous adenomas of advanced pathology. On the basis of multivariate analysis, two risk groups were identified: (1) patients with no parental history of colorectal carcinoma with only small $(\leqslant 10 \mathrm{~mm}$ ) tubular adenomas at the initial clearing examination have a very low risk, and we estimated that $10 \%$ will develop advanced metachronous adenomas after 10 years; (2) the high risk group contained all other patients, $10 \%$ of whom will show metachronous adenomas of advanced pathology at follow up after only three years.

Conclusions: The risk of developing metachronous adenomas with advanced pathology can be stratified for various patient and adenoma characteristics. Surveillance intervals can be scheduled for low risk (10 years) and high risk (three years) patients. Risk related follow up thus helps to avoid unnecessary examinations.
M ost colorectal carcinomas are believed to originate in pre-existing adenomas in accordance with the adenoma-carcinoma concept. ${ }^{12}$ The incidence of colorectal carcinoma can be significantly reduced by colonoscopic polypectomy and subsequent follow up. ${ }^{3-6}$ Periodic surveillance examinations have been considered necessary because of the high frequency of adenomatous polyps detected at follow up. ${ }^{4-7}$ A number of large follow up studies differ with regard to their recommendations for surveillance programmes. ${ }^{7-9}$ Recently, the recommended time interval between follow up examinations has been lengthened and defined by factors predicting the risk of finding adenomas with advanced pathology. ${ }^{6} 10 \mathrm{11}$

The aim of this study was to identify predictive variables on the basis of a multivariate analysis of a large series of patients on the Erlangen Registry of Colorectal Polyps, comprising prospectively documented cases who have been on a surveillance programme for approximately two decades. ${ }^{7}$ Adenoma size, histological type, site, and multiplicity, together with patient age and sex, are risk factors for the presence of high grade dysplasia or invasive carcinoma in adenomas. ${ }^{70-13}$ We investigated whether these risk factors of advanced pathology could also be used to predict the likely time interval to the development of metachronous adenomas of advanced pathology.

\section{MATERIALS AND METHODS}

The Erlangen Registry of Colorectal Polyps (ERCRP) was set up in 1978. All colorectal polyps removed via the endoscope in the Medical Department of the University of Erlangen were documented prospectively and classified histologically in the pathological department, in accordance with the WHO classification. ${ }^{14}$ Tubular adenomas were defined as those having up to $25 \%$ villous structure, tubulovillous adenomas as having $26-75 \%$, and villous adenomas as having more than $75 \%$. To date, 6829 adenomas have been diagnosed at the initial endoscopic examination and confirmed histopathologically in 3134 patients with no previous history of colorectal adenomas or carcinomas. Patients with a familial history of adenomatous polyposis or hereditary non-polyposis colon cancer syndrome, or inflammatory bowel disease were excluded. The size of small adenomas $(\leqslant 5 \mathrm{~mm})$ was estimated endoscopically by comparison with the open biopsy forceps, while all larger adenomas, which were removed completely, were measured accurately in the pathological department. All patients recorded in the registry were a place in a follow up programme. ${ }^{7}$ Patients with only a single initial adenoma were re-examined at four year intervals and those with multiple adenomas at two year intervals. A total of 1245 patients were identified as having at least one follow up examination after initial clearing total colonoscopy. Eighty six of these patients with adenomas containing invasive carcinoma at the initial examination were excluded.

\section{Statistical analysis}

Follow up records of 1159 patients undergoing surveillance examinations were used as a basis to identify factors that might determine the risk of metachronous adenomas developing during follow up. In accordance with Moertel, ${ }^{15}$ metachronous adenomas were defined as those detected more than 180 days after the initial clearing procedure.

Analyses were based on data from a registry containing patients with different durations of follow up, and showed

Abbreviations: ERCRP, Erlangen Registry of Colorectal Polyps; OR, odds ratio; RR, relative risk; NPS, National Polyp Study. 
Table 1 Adenoma characteristics at baseline examination in 1091 patients with, and 1849 patients without, surveillance

\begin{tabular}{|c|c|c|}
\hline Adenomas & $\begin{array}{l}\text { Follow up } \\
(\mathrm{n}(\%))\end{array}$ & $\begin{array}{l}\text { No follow up } \\
(\mathrm{n}(\%))\end{array}$ \\
\hline \multicolumn{3}{|l|}{ Size } \\
\hline$\leqslant 10 \mathrm{~mm}$ & 1725 (72.9) & 3338 (69.7) \\
\hline$>10 \mathrm{~mm}$ & 604 (25.5) & 1415 (29.5) \\
\hline No data & $38(1.6)$ & $39(0.8)$ \\
\hline \multicolumn{3}{|l|}{ Histological type } \\
\hline Tubular & $1820(76.9)$ & 3512 (73.3) \\
\hline Tubulovillous/villous & $508(21.5)$ & $1103(23.0)$ \\
\hline No data & $39(1.6)$ & $177(3.7)$ \\
\hline \multicolumn{3}{|l|}{ Location } \\
\hline Rectosigmoid & 1307 (55.2) & $2542(53.1)$ \\
\hline Proximal colon & $1060(44.8)$ & $2157(45.0)$ \\
\hline No data & $0(0.0)$ & $93(1.9)$ \\
\hline Total & 2367 & 4792 \\
\hline
\end{tabular}

deviations from the scheduled surveillance interval of up to one year. This made it impossible to use a simple design to calculate the proportion of patients with metachronous adenomas over a fixed time period in the subgroups of interest.

Odds ratios (ORs) or relative risks (RRs) for metachronous adenoma development in individual patient groups give only a qualitative impression of the increase in risk, but no indication of the time interval during which metachronous adenomas will develop. The aim of this study was to establish risk related time intervals after initial clearing colonoscopy to enable detection of adenomas before they reach the stage of advanced pathology.

An adenoma of advanced pathology is defined as larger than $10 \mathrm{~mm}$ in size or with high grade dysplasia or invasive carcinoma. ${ }^{8}$ The point in time at which an adenoma becomes an adenoma of advanced pathology cannot be observed directly but can be located between two follow up sessions. Therefore, observation of the time point at which an adenoma reached an advanced stage of development was the censored interval.

Regression methods for interval censored observations have recently been developed. We used a method proposed by Bebchuk and Betensky ${ }^{16}$ which permits an estimation of both the hazard function and the RRs for factors of interest. This

Table 2 Characteristics of adenomas at the initial clearing examination, and first metachronous lesions (histological type, size, and dysplasia are adenoma related and calculations of multiplicity are patient related)

\begin{tabular}{lcc}
\hline & $\begin{array}{l}\text { Initial finding } \\
(\mathrm{n}(\%))\end{array}$ & $\begin{array}{l}\text { 1st recurrence } \\
(\mathrm{n}(\%))\end{array}$ \\
\hline Histological type & & \\
$\quad$ Tubular & $1820(76.9)$ & $1095(83.8)$ \\
Tubulovillous/villous & $508(21.4)$ & $212(16.2)$ \\
No data & $40(1.7)$ & $4(0.3)$ \\
Size & & \\
$\leqslant 10 \mathrm{~mm}$ & $1725(72.8)$ & $1167(89.0)$ \\
$>0 \mathrm{~mm}$ & $604(25.5)$ & $127(9.7)$ \\
No data & $39(1.7)$ & $17(1.3)$ \\
Dysplasia & & $1284(97.9)$ \\
Low grade & $2267(95.7)$ & $27(2.1)$ \\
High grade & $101(4.3)$ & $0(0.0)$ \\
No data & $0(0.0)$ & $846(73.0)$ \\
Multiplicity & & $246(21.2)$ \\
Single & $623(53.8)$ & $67(5.8)$ \\
Multiple & $468(40.4)$ & \\
No data & $68(5.8)$ & \\
\hline
\end{tabular}

method allows quantification of the distribution of the time at which an adenoma becomes advanced. This allows calculation of the times required for $5 \%\left(\mathrm{t}_{0.05}\right), 10 \%\left(\mathrm{t}_{0.10}\right)$, or $20 \%\left(\mathrm{t}_{0.20}\right)$ of a given group of patients to develop adenomas of advanced pathology.

The accuracy of the quantiles $\mathrm{t}_{0.05}, \mathrm{t}_{0.10}$, and $\mathrm{t}_{0.20}$ is defined by calculating 95\% confidence intervals (CI) which form the basis for scheduling surveillance intervals. The lower boundaries of these $95 \%$ CIs are taken for the surveillance recommendations.

The following statistical procedures were performed:

(1) Multiple regression analysis based on the model of Bebchuk and Betensky. ${ }^{16}$

(2) Likelihood ratio tests to establish the model with the relevant risk factors and to assign patients to relevant risk groups.

(3) Calculation of the times $t_{0.05}, t_{0.10}$, and $t_{0.20}$ for the relevant risk groups based on their hazard functions.

(4) Creation of 1000 bootstrap samples ${ }^{17}$ of the data and application of the model of step 3 to the new data sets allows the study of the variations in the values of $\mathrm{t}_{0.05}, \mathrm{t}_{0.10}$, and $\mathrm{t}_{0.20}$. The percentile method was used to determine $95 \%$ CIs for those times. $^{18}$

Because of the interval censored data, graphical presentation of the probability of being free from advanced metachronous adenomas cannot use the Kaplan-Meier estimate, and therefore an algorithm proposed by Groeneboom and Wellner ${ }^{19}$ was used to calculate a non-parametric maximum likelihood estimate for the event time distribution in both risk groups.

All calculations were performed using the statistical software S-Plus 3.3 (MathSoft, Inc., Seattle, Washington, USA).

\section{RESULTS}

A total of 3134 patients undergoing endoscopic removal of colorectal adenomas between 1978 and 1996 were prospectively recorded on the Erlangen Registry of Colorectal Polyps (table 1). All patients were offered a chance to participate in a scheduled follow up programme. A total of 1849 patients ( $1178(63.7 \%)$ males, 671 (36.3\%) females) did not undergo surveillance. These patients either refused follow up or underwent examinations at other endoscopy departments. Single adenomas were found in 1052 patients (53.6\%) and 797 (46.4\%) had multiple initial lesions. Mean age at the initial clearing examination for patients who were followed up was 57.08 years (SD 11.25) compared with 59.74 (SD 11.61) for those who were not followed up. A total of 1159 patients underwent regular follow up examinations: 747 (64\%) of these patients were males and $412(36 \%)$ were females. One hundred patients $(8.6 \%)$ had a parental history of colorectal carcinoma while in 24 patients $(2.1 \%)$ the relevant data were not available. There were no statistically significant differences in baseline patient or adenoma characteristics between patients who underwent surveillance and those who did not.

\section{Initial and metachronous findings}

In $623(53.8 \%)$ patients a single adenoma, and in 468 (40.4\%) patients multiple adenomas were removed at the initial clearing examination. A total of $1820(76.9 \%)$ initial adenomas were classified as tubular, $446(18.8 \%)$ as tubulovillous, and 62 $(2.6 \%)$ as villous. In 101 (4.3\%) adenomas, high grade dysplasia was found during the initial examination. A total of 1725 $(72.8 \%)$ adenomas were $10 \mathrm{~mm}$ in diameter or smaller and $604(37.2 \%)$ were larger than $10 \mathrm{~mm}$ (table 2). We found 462 $(19.5 \%)$ adenomas in the rectum, $1245(52.6 \%)$ in the left colon, and $660(27.9 \%)$ in the right colon. 
Table 3 Multivariate analysis: risk factors for patients with tubular adenomas

\begin{tabular}{lll}
\hline Factor & RR & $95 \% \mathrm{Cl}$ \\
\hline Size $(>10 \mathrm{~mm})$ & 1.81 & $1.42-2.31$ \\
Multiplicity & 1.54 & $1.12-2.12$ \\
Parental history & 2.32 & $1.77-3.04$ \\
Size $(<10 \mathrm{~mm})$, male & 1 & \\
Size $(<10 \mathrm{~mm})$, female & 0.95 & $0.87-1.14$ \\
Size $(>10 \mathrm{~mm})$, male & 1.81 & $1.42-2.31$ \\
Size $(>10 \mathrm{~mm})$, female & 1.08 & $0.81-1.18$ \\
\hline \multicolumn{2}{l}{ RR, relative risk; Cl, confidence interval. } \\
\hline
\end{tabular}

Characteristics of the initial and metachronous findings are given in table 2 . In five patients the metachronous adenomas harboured invasive carcinoma. These lesions were detected in one patient after only one year and in other patients after 3, 4, 6 , or 11 years of follow up.

\section{Risk factors for advanced metachronous adenomas} Univariate analysis

The probability of being free of an advanced adenoma was calculated, with the aim of identifying patient and adenoma characteristics capable of predicting the development of metachronous adenomas with advanced pathology. In the overall sample, multiplicity $(p=0.0014)$ and size $(p<0.0001)$ of the initial adenoma were significant predictors. Stratification for histological type revealed no additional significant predictors for the 462 patients with tubulovillous or villous adenomas. These patients are therefore always at high risk of developing advanced metachronous adenomas. In patients with tubular adenomas only, multiplicity $(p=0.0069)$, size $(\mathrm{p}<0.0001)$, and a parental history of colorectal carcinoma $(p=0.0368)$ were significant predictors of advanced metachronous adenomas.

\section{Multivariate analysis}

Considering only patients with tubular adenomas at the initial clearing procedure, a multivariate model for related observations revealed that adenoma size $(\mathrm{p}<0.0001)$, multiplicity $(p=0.021)$, parental history of colorectal carcinoma $(\mathrm{p}=0.0168)$, and an interactive effect between size and sex $(p=0.00392)$ were significant predictive variables (table 3$)$. Male patients with large adenomas had a significantly higher risk of developing advanced metachronous adenomas than

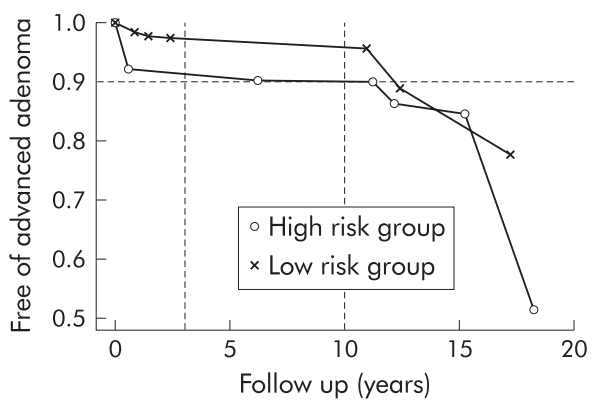

Figure 1 Probability of being free of metachronous adenomas of advanced pathology for the low risk and high risk groups.

other patients. Comparison of the probabilities of transition from non-advanced to advanced metachronous adenomas among the 16 subgroups (table 4 ) defined by combinations of the variables used in the multivariate analysis identified two risk groups (fig l): a low risk group containing patients with no parental history of colorectal carcinoma and with only small ( $\leqslant 10 \mathrm{~mm}$ ) tubular adenomas at the initial clearing examination, and a high risk group containing all other patients-that is, those with multiple or large adenomas, tubulovillous or villous adenomas, or a parental history of colorectal carcinoma. For the low risk group, we estimated that 12.2 (95\% CI 10.1-15.2) years were needed for advanced adenomas to develop in more than $10 \%$ of patients. For the high risk group the estimate was 6.1 (95\% CI 3.2-11.5) years. To determine how well the estimates reflected the (unknown) true 10\% quantile and to improve the effectiveness of surveillance for individual patients, we examined the lower boundary of the $95 \%$ CI of the $10 \%$ quantile. The vertical dotted lines in fig 1 mark the lower boundaries-that is, 10 years for the low risk group and three years for the high risk group.

If the $10 \%$ benchmark is changed and other quantiles are considered, the estimated times and the corresponding confidence intervals will also change. The estimate for the 5\% quantile (the time when not more than $5 \%$ of patients will develop advanced adenoma) is 0.5 years (95\% CI $0.1-1.6$ ) in the high risk group and 10.4 years (95\% CI 4.1-13.2) in the low risk group. The estimate for the $20 \%$ quantile (the time when not more than $20 \%$ of patients will develop an advanced adenoma) is 15.6 years (95\% CI 11.5-18.2) in the high risk group and 16.2 years (95\% CI 10.5-19.2) in the low risk group (table 5).

Table 4 Probability (P) of being free of advanced metachronous colorectal adenomas $(A A)$ in the 16 subgroups defined by the combinations of the variables used in the multivariate analysis

\begin{tabular}{llllc}
\hline $\begin{array}{l}\text { Variable combination } \\
\text { SX/SI/PH/MU }\end{array}$ & $\begin{array}{l}\text { P free from AA } \\
\text { after } 3 \text { years }\end{array}$ & $\begin{array}{l}\text { P free from AA after } \\
10 \text { years }\end{array}$ & High risk & Percentage \\
\hline 1111 & 0.962 & 0.905 & 0 & 18.85 \\
1112 & 0.942 & 0.857 & 1 & 13.72 \\
1121 & 0.913 & 0.793 & 1 & 2.00 \\
1122 & 0.870 & 0.700 & 1 & 1.53 \\
1211 & 0.932 & 0.834 & 1 & 14.39 \\
1212 & 0.897 & 0.757 & 1 & 16.86 \\
1221 & 0.849 & 0.657 & 1 & 1.67 \\
1222 & 0.777 & 0.524 & 1 & 1.20 \\
2111 & 0.909 & 0 & 10.46 \\
2112 & 0.964 & 0.864 & 1 & 7.06 \\
2121 & 0.945 & 0.802 & 1 & 0.87 \\
2122 & 0.918 & 0.712 & 1 & 0.33 \\
2211 & 0.876 & 0.897 & 1 & 5.40 \\
2212 & 0.959 & 0.846 & 1 & 4.33 \\
2221 & 0.937 & 0.778 & 1 & 0.33 \\
2222 & 0.907 & 0.679 & 1 & 1.00 \\
\hline
\end{tabular}

$\mathrm{SX}$, sex $1=$ male, $2=$ female; $\mathrm{SI}$, size $1=\operatorname{size}<10 \mathrm{~mm}, 2=$ size $=10 \mathrm{~mm} ; \mathrm{PH}$, parental history $1=$ no parenta history, $2=$ parental history; $M U$, multiplicity $1=$ single adenoma, $2=$ multiple adenomas. 
Table 5 Surveillance recommendations based on the quantiles $t_{0.05}, t_{0.10}$, and $t_{0.20}$

\begin{tabular}{llllll}
\hline & \multicolumn{2}{l}{ High risk } & & \multicolumn{2}{l}{ Low risk } \\
\cline { 2 - 3 } \cline { 5 - 6 } & Estimate & $95 \% \mathrm{Cl}$ & & Estimate & $95 \% \mathrm{Cl}$ \\
\hline $\mathrm{t}_{0.05}$ & $0.5 \mathrm{y}$ & $(0.1 ; 1.6 \mathrm{y})$ & & $10.4 \mathrm{y}$ & $(4.1 ; 13.2 \mathrm{y})$ \\
$\mathrm{t}_{0.10}$ & $6.1 \mathrm{y}$ & $(3.2 ; 11.5 \mathrm{y})$ & & $12.2 \mathrm{y}$ & $(10.1 ; 15.2 \mathrm{y})$ \\
$\mathrm{t}_{0.20}$ & $15.6 \mathrm{y}$ & $(11.5 ; 18.2 \mathrm{y})$ & & $16.2 \mathrm{y}$ & $(10.5 ; 19.2 \mathrm{y})$ \\
\hline
\end{tabular}

$\mathrm{Cl}$, confidence interval.

\section{DISCUSSION}

The incidence of colorectal carcinoma can be significantly reduced by colonoscopic polypectomy and subsequent follow up. ${ }^{3-6}$ Periodic surveillance examinations have been prompted by the high frequency (30-60\%) of adenomatous polyps detected at follow up ${ }^{4} 70-24$ compared with an incidence rate of approximately $16 \%$ at three years found in patients with no abnormalities at the index colonoscopy. ${ }^{25}$ Thus patients with a clean colon after initial polypectomy are believed to have a higher risk of developing metachronous adenomas or carcinomas than non-polyp carriers.

In accordance with the adenoma-carcinoma sequence, adenomas are recognised as precursor lesions of the vast majority of colorectal cancers. ${ }^{12}$ Several large studies carried out in recent years have identified the major factors determining the risk of developing high grade dysplasia and invasive carcinoma in an adenoma as tumour size and the amount of villous structure..$^{10-132627}$ An important question is whether these adenoma characteristics found at the initial examination can also predict the risk of metachronous adenomas and hence help in planning surveillance strategies.

Multiplicity of initial lesions was the first factor to be used as a suitable basis for scheduling different follow up intervals. Patients with multiple adenomas were re-examined every two years and patients with a single adenoma every four years, in accordance with their different risks of developing metachronous lesions.

Recently, a number of studies have proposed extending the follow up interval, ${ }^{628}$ in particular for patients with a very low risk of developing metachronous adenomas or carcinomas. A retrospective study from St Mark's Hospital, London, UK, found that patients with only a single small $(<10 \mathrm{~mm})$ tubular adenoma detected in the rectosigmoid were not at increased risk of subsequent colon cancer, and that surveillance may therefore be of no value in these patients. ${ }^{29}$ The King's Fund consensus panel in London then concluded that follow up should not be recommended for patients with a single small tubular rectal adenoma or patients over 75 years of age. $^{30}$ The Polyp Prevention Study Group concluded that patients with one or two tubular adenomas constitute a low risk group for whom follow up might be extended beyond three years. $^{28} 31$

The National Polyp Study (NPS) recently focused on differentiation of low and high risk patients, and modified its recommendations accordingly. ${ }^{32}$ A three year interval for screening colonoscopy is recommended for patients with multiple adenomas (especially three or more) at initial colonoscopy, and for those with a parental history of colorectal carcinoma and aged at least 60 years at the initial diagnosis. A six year or longer surveillance interval is recommended for adenoma patients with one or two adenomas and a negative family history of colorectal carcinoma, provided that all polyps detected initially were removed and total colonoscopy was performed. ${ }^{33}$ The different risk groups are defined by the number of initial lesions, the patient's age, and family history. Several studies have shown that patients with a family history of colorectal carcinoma are at increased risk of developing adenomatous polyps. ${ }^{34-36}$ However, the hypothesis that a history of colorectal carcinoma in any first degree relative increases an individual's risk of developing adenomas has not been supported by other studies. ${ }^{37}$ Conversely, siblings and parents of patients with adenomatous polyps have been reported to be at increased risk of colorectal carcinoma. ${ }^{39}$ In our study, a positive parental history of colorectal carcinoma proved to be a significant prognostic factor for the development of metachronous adenomas. However, the size of the largest initial lesion and villous structure were also of prognostic significance. These differences may be due to differences between the NPS samples and that of the Erlangen Registry in terms of the nature of the initial lesions and patient characteristics. The sample (NPS) included significantly more male patients $(\mathrm{p}=0.003)$, more patients older than 60 years $(p<0.0001)$, fewer large adenomas $(p=0.0001)$, and a larger number of tubular than tubulovillous or villous adenomas $(p<0.0001)$. No significant differences in the distribution of low and high grade dysplasia were found between the samples $(p=0.22)$.

Different conclusions may also result from different statistical methods applied. No publication has so far considered the problem of interval censored observations with respect to the event of interest. The transition to advanced pathology-that is, progress in the adenoma-carcinoma sequence-cannot be observed directly. It is only possible to register an existing state by inspection. Many authors apply classical standard methodology, such as Cox regression, to calculate relative risks. The use of Cox regression or Kaplan-Meier estimates for truly interval censored data results in over long surveillance intervals. For determination of follow up intervals, we calculated $5 \%, 10 \%$, and $20 \%$ quantiles of patients with metachronous adenomas of advanced pathology. The $10 \%$ quantile provided the best differentiation between high and low risk patients. Applying the 5\% quantile would have led to a very short interval (six months) for high risk patients and the $20 \%$ quantile would not have provided different risk related intervals (which was the intention of the study) for the two groups. Additionally, this cut off point may also be appropriate in terms of cost effectiveness. The following recommendations are therefore based on the $10 \%$ quantile.

In our view, the possibility that some of the adenomas found at follow up may be missed polyps ${ }^{40-42}$ and not true metachronous adenomas is of no relevance for the calculation of clinical surveillance recommendations.

\section{Surveillance recommendations}

The results of the multivariate analysis of time intervals for the detection of advanced metachronous adenomas form the basis of our follow up recommendations. We distinguish two degrees of risk for the development of advanced metachronous adenomas: low risk and high risk. Patients with a low risk-that is, no parental history of colorectal carcinoma and only single or small $(\leqslant 10 \mathrm{~mm})$ tubular adenomas at the initial clearing — can safely wait 10 years for their first surveillance examination. Patients with a high risk of developing metachronous adenomas of advanced pathology — that is, all other patients_-should have their first follow up examination no later than three years after the initial clearing.

All surveillance examinations should be performed as complete colonoscopies up to the caecum because of the high rate of metachronous adenomas located in the right colon. ${ }^{43}$

Surveillance programmes should be centralised at regional computerised registries so as to reliably ensure that patients are reminded to attend for the re-examination, even after 10 years.

\section{ACKNOWLEDGEMENT}

Part of this work was supported by a grant from the Johannes and Frieda Marohn-Stiftung Erlangen, Germany. 


\section{Authors' affiliations}

G Nusko, E G Hahn, Department of Medicine I, University of Erlangen, Germany

U Mansmann, Institute of Medical Biometry and Informatics, University of Heidelberg, Germany

Th Kirchner, Department of Pathology, University of Erlangen, Germany

\section{REFERENCES}

1 Muto T, Bussey HJR, Morson BC. The evolution of cancer of the colon and rectum. Cancer 1975;36:2251-70.

2 Morson BC. Evolution of cancer of the colon and rectum. Cancer 1974;34:845-9.

3 Winawer SJ, Zauber AG, Ho MN, et al. Prevention of colorectal cancer by colonoscopic polypectomy. N Engl J Med 1993;392:1977-81.

4 Jorgensen OD, Kronborg O, Fenger C. The Funen Adenoma Follow-up Study. Incidence and death from colorectal carcinoma in the adenoma surveillance program. Scand J Gastroenterol 1993;28:869-74.

5 Müller AD, Sonnenberg A. Prevention of colorectal cancer by flexible endoscopy and polypectomy. A case-control study of 32702 veterans. Ann Intern Med 1995; 123:904-10.

6 Hoff G, Sauar J, Vatn MH, et al. Polypectomy of adenomas in the prevention of colorectal cancer: 10 years follow-up of the Telemark polyp study I. . Scand J Gastroenterol 1996;31:1006-10.

7 Matek W, Guggenmoos-Holzmann I, Demling L. Follow-up of patients with colorectal adenomas. Endoscopy 1985;17:175-81.

8 Winawer SJ, Zauber AG, O'Brien M, et al. Randomized comparison of surveillance intervals after colonoscopic removal of newly diagnosed adenomatous polyps. N Engl J Med 1993;328:901-6.

9 Jorgensen OD, Kronborg O, Fenger $C$. A randomized surveillance study of patients with pedunculated and small sessile tubular and tubulovillous adenomas. The Funen Adenoma Follow-up Study. Scand J Gastroenterol 1995;30:686-92.

10 O'Brien MJ, Winawer SJ, Zauber AG, et al. The national polyp study. Patient and polyp characteristics associated with high-grade dysplasia in colorectal adenomas. Gastroenterology 1990;98:371-9.

11 Jorgensen OD, Kronborg O, Fenger C. The Funen Adenoma Follow-Up Study. Characteristics of patients and initial adenomas in relation to severe dysplasia. Scand J Gastroenterol 1993;28:239-43.

12 Nusko G, Mansmann U, Altendorf-Hofmann A, et al. Differences between colorectal adenomas removed endoscopically and surgically. Multivariate analysis of patient and polyp characteristics of the risk for high-grade dysplasia. Hepato-Gastroenterol 1997;44:1063-8.

13 Hermanek P, Frühmorgen P, Guggenmoos-Holzmann I, et al. The malignant potential of colorectal polyps $-A$ new statistical approach. Endoscopy 1983;15:16-20.

14 Jass JR, Sobin LH. Histological typing of intestinal tumours. WHO international classification of tumours 2nd edn. Berlin: Springer, 1989.

15 Moertel CG, Bargen JA, Dockerty MB. Multiple carcinomas of the large intestine. A review of the literature and a study of 261 cases. Gastroenterology 1958;34:85-98.

16 Bebchuk JD, Betensky RA. Multiple imputation for simple estimation of the hazard function based on interval censored data. Stat Med 2000;19:405-19.

17 Sauerbrei $\mathbf{W}$. The use of resampling methods to simplify regression models in medical statistics. Appl Stat 1999;48:313-29.

18 Davison AC, Hinkley DV. Bootstrap methods and their application. Cambridge: Cambridge University Press, 1998.

19 Groeneboom P, Wellner J. Information bounds and nonparametric maximum likelihood estimation. Basel: Birkhäuser, 1992.

20 Brenna E, Skreden K, Waldum HL. The benefit of colonoscopy. Scand J Gastroenterol 1990;25:81-8.
21 Nava H, Carlsson G, Petrelli NJ, et al. Follow-up colonoscopy in patients with colorectal adenomatous polyps. Dis Colon Rectum 1987; 30:465-8. 22 Neugut Al, Johnsen CM, Forde KA, et al. Recurrence rates for colorectal polyps. Cancer 1985;55:1586-9.

23 Waye JD, Braunfeld S. Surveillance intervals after colonoscopic polypectomy. Endoscopy 1982;14:79-81

24 Woolfson IK, Eckholdt GJ, Wetzel CR. Usefulness of performing colonoscopy one year after endoscopic polypectomy. Dis Colon Rectum 1990;33:389-93.

25 Neugut Al, Jacobson JS, Ahsan $\mathrm{H}$, et al. Incidence and recurrence rates of colorectal adenomas: A prospective study. Gastroenterology 1995; 108:402-8

26 Nusko G, Mansmann U, Partzsch U, et al. Invasive carcinoma in colorectal adenomas. Multivariate analysis of patient and adenoma characteristics. Endoscopy 1997;29:626-31.

27 Nusko G, Sachse R, Mansmann U, et al. K-ras-2 gene mutations as predictors of metachronous colorectal adenomas. Scand J Gastroenterol 1997;32:1035-41.

28 van Stolk RU, Beck GJ, Baron JA, et al. Adenoma characteristics at first colonoscopy as predictors of adenoma recurrence and characteristics at follow-up. Gastroenterology 1998;115:13-18.

29 Atkin WS, Morson BC, Cuzick J. Long-term risk of colorectal cancer after excision of rectosigmoid adenomas. N Engl J Med 1992;326:658-62.

30 Pollock AM, Quirke P. Adenoma screening and colorectal cancer. The need for screening and polypectomy is unproved. BM 1991;303:3-4

31 Noshirwami KC, van Stolk RU, Rybicki LA, et al. Adenoma size and number are predictive of adenoma recurrence: implications for surveillance colonoscopy. Gastrointest Endosc 2000;51:433-7.

32 Zauber AG, Winawer SJ. Initial management and follow-up surveillance of patients with colorectal adenomas. Gastroenterol Clin North Am 1997;26:85-101

33 Zauber AG, Winawer SJ, Bond JH, et al. Can surveillance intervals be lengthened following colonoscopic polypectomy? Gastroenterology 1997; 112:A50.

34 Grossman S, Milos ML. Colonoscopic screening of persons with suspected risk factors for colon cancer I. Family history. Gastroenterology 1988:94:395-400

35 St John DJB, Mc Dermott FT, Hopper JL, et al. Cancer risk in relatives of patients with common colorectal cancer. Ann Intern Med 1993; 1 18:785-90.

36 Bazzoli F, Fossi S, Sottili S, et al. The risk of adenomatous polyps in asymptomatic first-degree relatives of persons with colon cancer. Gastroenterology 1995; 109:783-8.

37 Guillem JG, Forde KA, Treat MR, et al. Colonoscopic screening for neoplasms in asymptomatic first-degree relatives of colon cancer patients. A controlled, prospective study. Dis Colon Rectum 1992;35:523-9.

38 Aitken JF, Bain CJ, Ward M, et al. Risk of colorectal adenomas in patients with a family history of colorectal cancer: some implications for screening programmes. Gut 1996;39:105-8.

39 Winawer SJ, Zauber AG, Gerdes H, et al. Risk of colorectal cancer in the families of patients with adenomatous polyps. N Engl J Med 1996;334:82-7.

40 Rex DK, Cutler CS, Lemmel GT, et al. Colonoscopic miss rates of adenomas determined by back-to-back colonoscopies. Gastroenterology 1997; 112:24-8.

41 Hixson LJ, Fennerty MB, Sampliner RE, et al. Prospective blinded trial of the colonoscopic miss rate of large colorectal polyps. Gastrointest Endosc $1991 ; 37: 125-7$.

42 Hixson LS, Fennerty MB, Sampliner RE, et al. Prospective study of the frequency and size distribution of polyps missed by colonoscopy. J Natl Cancer Inst 1990;82:1769-72.

43 Nusko G, Mansmann U, Wiest G, et al. Right-sided shift found in metachronous colorectal adenomas. Endoscopy 2001;33:574-9. 